Saudi Journal of Oral and Dental Research

Abbreviated Key Title: Saudi J Oral Dent Res

ISSN 2518-1300 (Print) |ISSN 2518-1297 (Online)

Scholars Middle East Publishers, Dubai, United Arab Emirates

Journal homepage: https://saudijournals.com/sjodr

\title{
Impact of Education on Dental Anxiety among the Patients Visiting Public Dental Hospitals in Pakistan
}

\author{
Hafiza Armish Siraj ${ }^{1}$, Umair Hussain ${ }^{2}$, Shanza Rehman ${ }^{3}$, Shah Bano Khan ${ }^{4}$, Amina Tariq ${ }^{4 *}$ \\ ${ }^{1}$ de, Montmorency College of Dentistry, Fort Rd, Shahi Mohallah Walled City of Lahore, Lahore, Punjab, Pakistan \\ ${ }^{2}$ Nishtar Institute of Dentistry, This is postal address of my house, Jinnah Town, Google it. I keep receiving mail of NID due to this. Kindly correct, \\ 120/12 Jail Rd, across the road in, Jinnah Town, Multan, Punjab, Pakistan \\ ${ }^{3}$ Dental Section, Punjab Medical College, Sargodha Road, Faisalabad, Punjab 38000, Pakistan \\ ${ }^{4}$ University College of Dentistry, The University of Lahore, 1- Km Raiwind Rd, Sultan Town, Lahore, Punjab, Pakistan
}

DOI: $10.36348 /$ sjodr.2020.v05i07.004

| Received: 28.06.2020 | Accepted: 06.07.2020 | Published: 12.07.2020

*Corresponding author: Amina Tariq

\section{Abstract}

Aim: This study was designed while aiming that this study explore the association between educational level and level of dental anxiety among patients in Pakistan. Method: The current study was based on descriptive cross-sectional research design. Data was collected from the patients of public sector dental hospital of Lahore. Data was collected from 160 patients who visited dental hospital at surveying time and participated in the study as volunteers. To explore the relationship of educational level with regards to dental anxiety among patients, Chi square was used. Results: The results of Chi-Square revealed that educational level and dental anxiety showed significant difference $\left(\mathrm{X}^{2}=125.867, \mathrm{P}>.001\right)$. Mild dental anxiety among patients with below matric education was higher (80\%) followed by patients with education level of matriculation (70\%), then came patients with Higher secondary school education (52\%) and patients with graduation degree were $35 \%$. With moderate to severe dental anxiety, patients with graduation degree were found to be higher $(38 \%)$ and at lower level were the patients below matric education level (10\%). Patients with dental phobia were found more in the category of graduated patients (27\%) and least in patients below matric (10\%). Conclusion: In conclusion, educational level was found to be significant with dental anxiety levels in the patients coming to the public dental hospitals in Pakistan. Factors behind these findings should be explored to fill the gap literature as patients with higher educational level have higher level of dental anxiety which is in opposite of previous literature.

Keywords: Dental anxiety, Phobia, Education, Dental fear.

Copyright @ 2020: This is an open-access article distributed under the terms of the Creative Commons Attribution license which permits unrestricted use, distribution, and reproduction in any medium for non-commercial use (NonCommercial, or CC-BY-NC) provided the original author and source are credited.

\section{INTRODUCTION}

Dental anxiety or dental fear among children has been documented in numerous countries as a dilemma in public health [1], which has been explore at a much extended level. Anxiety is defined as a pathological condition is definite with extreme emotional state of fear, complemented by somatic signs related with over-reactivity of the autonomic nervous system [2, 3]. Whereas Dental anxiety is a state of strong physiological reactions concerning any dental treatment. It is a state that prolongs from the earlier experience to the present condition and stops the patients to enjoy dental treatment benefits taking [4]. Mostly, it was concluded that dental anxiety patients have negative beliefs linked with any dental treatment or dentist and have a tendency to overstress events related to dental treatment. For instance, a short term and simple dental treatment after local anesthesia could be called a very traumatic and challenging experience for the patient $[5,6]$. As a result, people with higher level of dental anxiety have a habit of delaying their dental treatment constantly that mediates the early intrusions and consequences in worsening of oral health issues. Childhood traumatic dental treatment is the major and highly important cause of developing dental anxiety among patients. But, the family attitude towards dental treatment is also considerable factor as it is an actual factor in dental anxiety development, as well as anxious temperament and socio-environmental aspects $[7,8]$. Individuals with dental anxiety are not a uniform group; the occurrence is greater among females and people with low wages $[7,8]$. The association of age and education has been studied to explore the level of dental anxiety but there contradictory results were obtained. Different research studies has been performed to explore the association between level of dental anxiety and education. Few of which showed that better education level allows the patient to cope better with 
dental anxiety and have less dental anxiety level. However other showed no association between level of education and anxiety of dental treatment [8-10]. So, for explore this association in a better way among Pakistani population as lower-middle income country with lower literacy rate, this study was designed while aiming that this study explore the association between educational level and level of dental anxiety among patients in Pakistan.

\section{METHODOLOGY}

The current study was based on descriptive cross-sectional research design. Data was collected from the patients of public sector dental hospital of Lahore. Educational level was taken as demographic and for measuring the dental anxiety level Modified Dental Anxiety Scale ${ }^{11}$ was used. It consisted of five questions rated on five-point Likert scale. The range of score lies between 5 to 25 . The range of scores for mild anxiety scores lies between 5 to 10 , for moderate to severe level of anxiety score ranges from 11-18, and for dental phobia, the scores ranges from 19-25. Data was collected from 160 patients who visited dental hospital at surveying time and participated in the study as volunteers. After taken written consent from the patients data was collected. To explore the relationship of educational level with regards to dental anxiety among patients, Chi square was used. A $\mathrm{p}$ value of $\leq 0.05$ was set as the level for statistical significance.

\section{RESULTS}

The results of Chi-Square revealed that educational level and dental anxiety showed significant difference $\left(\mathrm{X}^{2}=125.867, \mathrm{P}>.001\right)$. Mild dental anxiety among patients with below matric education was higher $(80 \%)$ followed by patients with education level of matriculation $(70 \%)$, then came patients with Higher secondary school education (52\%) and patients with graduation degree were $35 \%$. With moderate to severe dental anxiety, patients with graduation degree were found to be higher $(38 \%)$ and at lower level were the patients below matric education level (10\%). Patients with dental phobia were found more in the category of graduated patients $(27 \%)$ and least in patients below matric (10\%).

Table-1: Dental anxiety among patients with different educational levels

\begin{tabular}{|c|c|c|c|c|c|c|}
\hline & \multicolumn{3}{|c|}{ Dental anxiety level } & \multirow[t]{2}{*}{$\mathbf{X}^{2}$} & \multirow[t]{2}{*}{ Sig. } \\
\hline & & Mild Anxiety & Moderate to Severe & Phobia & & \\
\hline \multirow[t]{4}{*}{ Educational Level } & Below Matric & $80.0 \%$ & $10.0 \%$ & $10.0 \%$ & \multirow[t]{4}{*}{125.867} & \multirow[t]{4}{*}{0.00} \\
\hline & Matric & $70.0 \%$ & $20.0 \%$ & $10.0 \%$ & & \\
\hline & Intermediate & $52.0 \%$ & $27.0 \%$ & $21.0 \%$ & & \\
\hline & Graduation & $35.0 \%$ & $38.0 \%$ & $27.0 \%$ & & \\
\hline
\end{tabular}

\section{DISCUSSION}

The aim of the study was to explore the prevalence of dental anxiety among the patients with different educational levels. It was explored that educational level and dental anxiety showed significant difference. Mild dental anxiety among patients with below matric education was higher followed by patients with education level of matriculation, and then came patients with higher secondary school education and then patients with graduation degree. With moderate to severe dental anxiety, patients with graduation degree were found to be higher and at lower level were the patients below matric education level. Patients with dental phobia were found more in the category of graduated patients and least in patients below matric. According to Saatchi et al., [9], better education level allows the patient to cope better with dental anxiety and have less dental anxiety level but the results of present study showed that better education causes higher level of dental anxiety may be due to understanding of maximum worse which could be done by the any dental treatment. Whereas the results of current study negates the outcomes of previous studies showed no significant relationship of dental anxiety levels with education [10].
In conclusion, educational level was found to be significant with dental anxiety levels in the patients coming to the public dental hospitals in Pakistan. Factors behind these findings should be explored to fill the gap literature as patients with higher educational level have higher level of dental anxiety which is in opposite of previous literature.

\section{REFERENCES}

1. Hunt, C. (2000). The diagnosis and nature of generalized anxiety disorder. Current Opinion in Psychiatry, 13(2), 157-161.

2. Connor, K. M., \& Davidson, J. R. (1998). Generalized anxiety disorder: neurobiological and pharmacotherapeutic perspectives. Biological Psychiatry, 44(12), 1286-1294.

3. Ozlek, E., Yıldırım, A., Koc, A., \& Boysan, M. (2019). Socio-Demographic Determinants of Dental Anxiety and Fear Among College Students. Eastern Journal of Medicine, 24(2), 169175.

4. Carrillo- Diaz, M., Crego, A., Armfield, J. M., \& Romero- Maroto, M. (2012). Assessing the relative efficacy of cognitive and non- cognitive factors as predictors of dental anxiety. European journal of oral sciences, 120(1), 82-88. 
5. De Jongh, A., Muris, P., Ter Horst, G., Van Zuuren, F. J., \& De Wit, C. A. (1994). Cognitive correlates of dental anxiety. Journal of Dental Research, 73(2), 561-566.

6. Firat, D., Tunc, E. P., \& Sar, V. (2006). Dental anxiety among adults in Turkey. $J$ Contemp Dent Pract, 7(3), 75-82.

7. Tunc, E. P., Firat, D., Onur, O. D., \& Sar, V. (2005). Reliability and validity of the Modified Dental Anxiety Scale (MDAS) in a Turkish population. Community dentistry and oral epidemiology, 33(5), 357-362.

8. Armfield, J. M., Slade, G. D., \& Spencer, A. J. (2008). Cognitive vulnerability and dental fear. BMC oral health, $8(1): 1-11$.
9. Saatchi, M., Abtahi, M., Mohammadi, G., Mirdamadi, M., \& Binandeh, E. S. (2015). The prevalence of dental anxiety and fear in patients referred to Isfahan Dental School, Iran. Dental research journal, 12(3), 248-253.

10. Ozlek, E., Yıldırım, A., Koc, A., \& Boysan, M. (2019). Socio-Demographic Determinants of Dental Anxiety and Fear Among College Students. Eastern Journal of Medicine, 24(2), 169175.

11. What is a Dental Anxiety Scale? Dental Brothers [Internet]. Dental Brothers2018 [cited 2018 Nov 7]. Available from: https://www.dentalbrothers.com/what-is-a-dentalanxiety-scale/ 